\title{
La investigación y vinculación en las Universidades Públicas
}

\author{
J. Selva Andina Res. Soc. 2018; 9(2):64-65.
}

La investigación científica y la vinculación, son categorías indispensables de la academia y en general de las universidades en el Ecuador (Velázquez \& Velástegui 2015). Según la LOES (2015), la educación superior de carácter humanista, cultural y científica constituye un derecho de las personas y un bien público social que, de conformidad con la Constitución de la República, responderá al interés público y no estará al servicio de intereses individuales y corporativos.

Razón por la cual se acredita la importancia que se le da, por el estado ecuatoriano, a la investigación científica como un servicio de utilidad sociocultural y económica, encaminado al bienestar humano, atendiendo al principio del Buen Vivir. En la misma ley se determinan como derechos de los estudiantes, “... completar su formación bajo la más amplia libertad de cátedra e investigativa...”, así como “... participar en el proceso de construcción, difusión y aplicación del conocimiento." (CES 2015). Estos elementos coinciden en un desarrollo personal y social, con la aplicación de la ciencia, a través de investigaciones. También los profesores, todos, sean o no investigadores, tienen dentro de sus derechos “....acceder a la carrera de profesor e investigador... basados en el mérito académico,..., en la producción investigativa, en el perfeccionamiento permanente,... participar en el proceso de construcción, difusión y aplicación del conocimiento...” (CES 2015).

Se vislumbra que, los agentes más importantes de la educación superior en Ecuador, los estudiantes y sus profesores, están amparados en el desarrollo de un pensamiento científico humanista, con objetivos bien definidos, y que se manifiesten en el bienestar social, en el desarrollo de cada uno de los territorios que pertenecen al entorno de influencia de las universidades. Dentro de los principios declarados en el Reglamento del Régimen Académico el Consejo de Educación Superior (CES 2015), está el de “... regular la gestión académica-formativa en todos los niveles de formación y modalidades de aprendizaje de la educación superior, con miras a fortalecer la investigación, la formación académica y profesional, y la vinculación con la sociedad".

Además, se declara como otros de los principios, en este mismo reglamento, “... articular la formación académica y profesional, la investigación científica, tecnológica y social, y la vinculación con la colectividad, en un marco de calidad, innovación y pertinencia..., impulsar el conocimiento de carácter multi, inter y trans disciplinarios en la formación de grado y posgrado, la investigación y la vinculación con la colectividad." El reglamento al que se hace referencia, en cuanto a la vinculación con la sociedad y educación continua, plantea que "La vinculación con la sociedad hace referencia a los programas de educación continua, investigación y desarrollo, y gestión académica, en tanto respondan, a través de proyectos específicos, a las necesidades del desarrollo local, regional y nacional. Las instituciones de educación superior deberán crear obligatoriamente instancias institucionales específicas para planificar y coordinar la vinculación con la sociedad, a fin de 
generar proyectos de interés público.”

\section{Literatura citada}

Consejo de Educación Superior. Ley Orgánica de Educación Superior (LOES) del Ecuador. 2018. Recuperado de: http://www.ces.gob.ec/descargas/ley-organicade-educacion-superior.

Ley Orgánica de Educación Superior. 2018 Recuperado de https://procuraduria.utpl.edu.ec/sitios/documentos /NormativasPublicas/Ley\%20Org\%C3\%A1nica\%20de\%20Educaci\%C3\%B3n\%20Superior\%20Codi ficada.pdf.

Velázquez MR, Velástegui ME. Investigación y vinculación: por el camino a una integración necesaria en la universidad ecuatoriana. Rev Cs Tec Innov 2015;2(2):116-37.

Julio Gabriel-Ortega

Facultad de Ciencias Naturales y de la Agricultura

Universidad Estatal del Sur

de Manabí (UNESUM), km 1.5 vía

Noboa, Campus los Ángeles

Jipijapa, Manabí, Ecuador

Telf. +593052600229

E-mail. Julio.gabriel@unesum.edu.ec 